International Journal of Public Health Excellence (IJPHE)

Vol. 1, No. 1, January 2022, pp. 35 40

Journal homepage: https://ejournal.ipinternasional.com/index.php/ijphe

ISSN: 2809-9826, DOI: https://doi.org/10.55299/ijphe.v1i1.10

\title{
Factors Related to the Event of Macrosomia in Infants at the Atikah Clinic for the Period of 2018-2020
}

\author{
Helmi Wardah Nasution ${ }^{1}$ \\ ${ }^{1}$ Midwifery Diploma 3 Study Program, Madina Husada Midwifery Academy, Indonesia
}

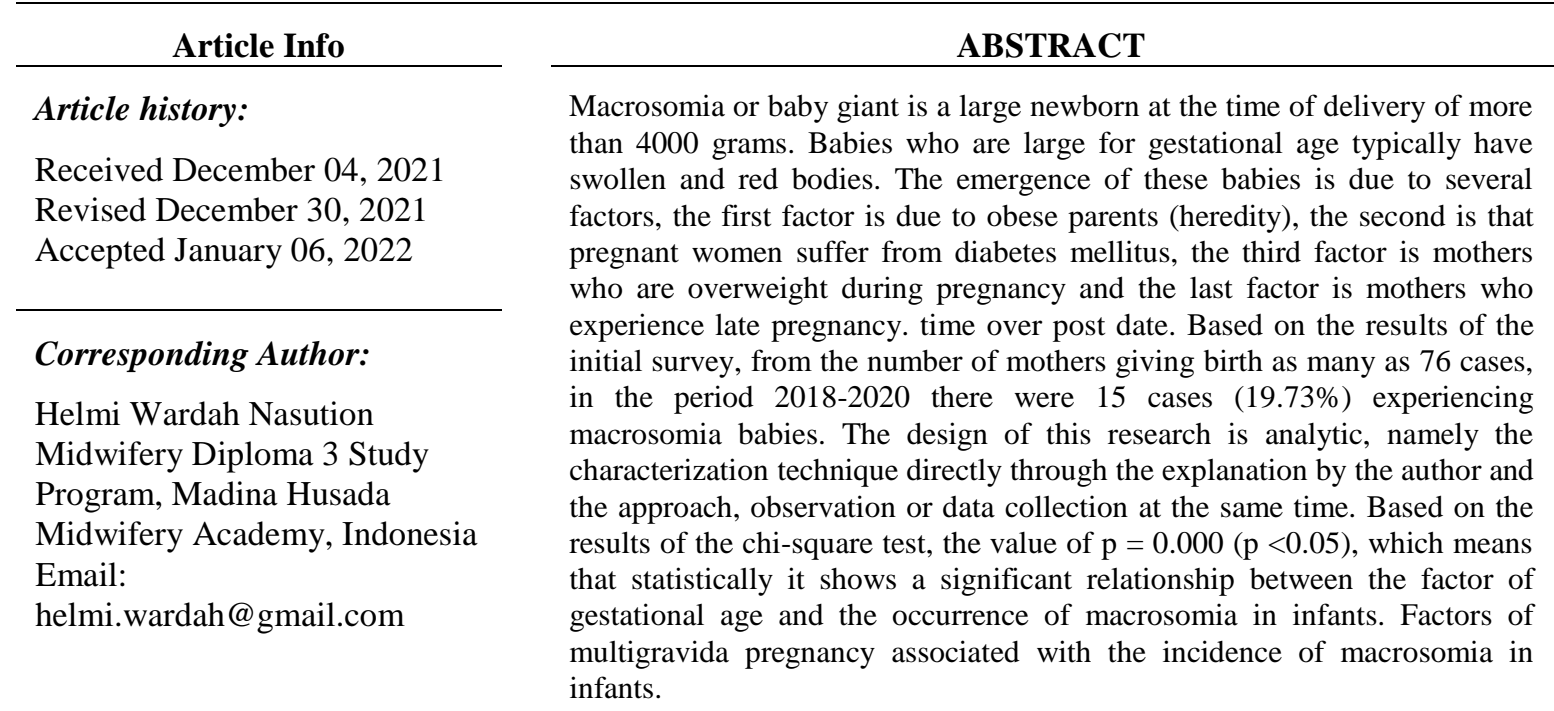

Keywords:

Factors, Related, Event, Macrosomia, Baby

This article is licensed under a Creative Commons AttributionShareAlike 4.0 International License.

\section{INTRODUCTION}

Macrosomia or baby giant is a large newborn at the time of delivery of more than 4000 grams. These large newborns are usually born at term. Babies who are large during pregnancy typically have swollen and red bodies (Yulianti and Rukiyah, 2017). The emergence of these babies is due to several factors, the first factor is due to obese parents (heredity), the second is that pregnant women suffer from diabetes mellitus, the third factor is mothers who are overweight during pregnancy and the last factor is mothers who experience late pregnancy. time over post date

The infant mortality rate in Indonesia is quite high, namely per 1000 live births. In 2011, Southeast Asia was ranked the second highest for under-five mortality due to asphyxia due to too large babies (macrosomia), worldwide there was an increase of $15-25 \%$ of women giving birth to macrosomic babies. significantly from $16.7 \%$ to $20 \%$ in Sweden, and from $9.1 \%$ to $10.1 \%$ in Germany 2011. Macrosomia is caused by many factors, the first factor is the mother has a history of giving birth to a macrosomic baby, the mother in her first pregnancy gives birth to macrosomia, has a high chance of giving birth to a second child with the same condition in her next pregnancy. The factor is not the first pregnancy, there is a tendency for the birth weight of the second child and so on to be greater than the first child (Maryunani and Puspita, 2014). Another cause of macrosomia is a mother carrying a male baby, in general, a male fetus will be larger than a female fetus. The second is that pregnancy occurs at the age of over 35 years, women should be pregnant before that age so as not to get a lot of side effects. And the third factor is that pregnancy occurs longer and exceeds the predetermined time of birth [4].

Based on the results of the initial survey at the Atikah Midwife Clinic, from the number of mothers giving birth as many as 76 cases, in the 2018-2020 period there were 15 cases (19.73\%) experiencing macrosomic babies. From the description of the background above, the researchers conducted a study entitled "Factors that cause macrosomia in infants. Macrosomia has signs that are visible or can be felt. Doctors are usually aware of this 
condition so that complications do not occur. The signs of macrosomia are abdominal size that is larger than expected, significant weight gain, knowing the size of the baby by ultrasound, and having lots of amniotic fluid in the uterus, especially the one that covers the baby [5]

Complications due to macrosomia consist of difficulty for the fetus to be born to injury to the mother and fetus. Babies also have the possibility of hypoglycemia from birth. Obesity since childhood can also occur, respiratory problems, to the most dangerous is infant death. Pregnant women can also experience bleeding, organ damage, postpartum trauma, and death. Given the risk on both sides is very risky, it helps us pay more attention to the health problems of pregnant women. Nutrients and food may be consumed, remain in good control so that obesity does not occur in babies from in the womb [6].

\section{METHOD}

The design of this research is analytic, namely the characterization technique directly through an explanation by the author without being complicated with a cross sectional study approach, namely research to study the dynamics of the correlation between risk factors and effects, by approach, observation or data collection at the same time at the same time. the same [3]. The population is a generalization area consisting of objects/subjects that have certain quantities and characteristics that are determined by the researcher to be studied and then conclusions are drawn [1]. The population in this study were all 33 mothers who gave birth to macrosomic babies at the Atikah Midwife Clinic in the period 2018-2020.

The sampling method in this study is to use a total sampling technique, namely a sampling technique where the number of samples is 33 people equal to the population [3]. Data collection used secondary data obtained from Medical Records using a questionnaire in the form of a checklist sheet containing the factors associated with the cause of macrosomia in infants consisting of a history of pregnancy, multigravida pregnancy, male gender, maternal age and gestational age. Data analysis is the process of systematically searching and compiling data obtained from interviews, field notes, and other materials, so that they can be more easily understood, and all of which can be informed to others.

\section{RESULTS AND DISCUSSION}

Atikah Midwife Clinic provides various facilities for public health services, such as building and transportation facilities consisting of 1 inpatient room measuring $3 \times 4$ meters in good condition, 1 delivery room measuring $4 \times 4$ meters in good condition, 1 patient treatment room measuring $3 \times 3$ meters in good condition, 2 bathrooms, 1 waiting room, 1 kitchen, 1 clothes drying room, availability of water, electricity. The Midwife Atikah Clinic also provides public facilities at the clinic, which consist of running water facilities, sinks and maternity hospital infrastructure, medical equipment, examination instruments, infection prevention facilities, infection prevention materials, and contraceptives.

\subsection{Results}

Table 1. Macrosomia Incidence in Infants at the Atikah Midwife Clinic for the 2018-2020 period

\begin{tabular}{lll}
\hline The Occurrence of Macrosomia in Babies & Frequency & $\%$ \\
\hline No Macrosomia $(\leq 4000 \mathrm{gr})$ & 147 & 81,7 \\
\hline Macrosomia $(>4000 \mathrm{gr})$ & 33 & 18,3 \\
\hline Amount & 180 & 100,0 \\
\hline
\end{tabular}

Based on table 1. it can be seen that the incidence of macrosomia in infants $(>4000 \mathrm{~g})$ was 33 respondents $(18.3 \%)$, while infants who were not macrosomia $(\leq 4000 \mathrm{~g})$ were 147 respondents $(81.7 \%)$.

Table 2. Cross Tabulation of Birth History Factors with Large Babies Associated with Macrosomia Incidence in Babies

\begin{tabular}{c|cccccc|c}
\hline \multicolumn{7}{|c|}{ The Occurrence of Macrosomia in Babies } & \multirow{2}{*}{ P-Value } \\
\hline $\begin{array}{c}\text { History of } \\
\text { giving birth } \\
\begin{array}{c}\text { to a big } \\
\text { baby }\end{array}\end{array}$ & No Macrosomia $(\leq 4000 \mathrm{~g})$ & Macrosomia $(>4000 \mathrm{~g})$ & & Total & \\
\hline No & 146 & $\%$ & $\mathrm{~F}$ & $\%$ & $\mathrm{~F}$ & $\%$ & \\
\hline Yes & 1 & 86,9 & 22 & 13,1 & 168 & 100,0 & \multirow{2}{*}{0,00} \\
\hline Total & 147 & 8,3 & 11 & 91,7 & 12 & 100,0 & \\
\hline
\end{tabular}

The table above shows that of the 168 respondents who did not have a history of giving birth to large babies, $13.1 \%$ experienced macrosomia, and $86.9 \%$ did not. Meanwhile, of the 12 respondents who had a history of giving birth to large babies, $91.7 \%$ experienced macrosomia and $8.3 \%$ did not. The percentage of 
macrosomia in mothers who have a history of giving birth to large babies is higher than the incidence of macrosomia in mothers who have never given birth to large babies. Based on the results of the chi-square test, the $\mathrm{p}$ value $=0.000(\mathrm{p}<0.05)$, which means that statistically it shows a significant relationship between the history of giving birth to large babies and the occurrence of macrosomia in infants at the Atikah Midwife Clinic for the 2018-2020 period.

Table 2. Cross Tabulation of Multigravida Pregnancy Factors Associated with Macrosomia Incidence in Infants The Occurrence of Macrosomia in Babies

\begin{tabular}{|c|c|c|c|c|c|c|c|}
\hline \multicolumn{8}{|c|}{ The Occurrence of Macrosomia in Babies } \\
\hline \multirow{2}{*}{$\begin{array}{c}\text { Multigravida } \\
\text { Pregnancy }\end{array}$} & \multicolumn{2}{|c|}{ No Macrosomia $(\leq 4000 \mathrm{~g})$} & \multicolumn{2}{|c|}{ Macrosomia $(>4000 \mathrm{~g})$} & \multicolumn{2}{|c|}{ Total } & \multirow{2}{*}{ P-Value } \\
\hline & $\mathrm{F}$ & $\%$ & $\mathrm{~F}$ & $\%$ & $\mathrm{~F}$ & $\%$ & \\
\hline No & 145 & 92,4 & 12 & 7,6 & 157 & 100,0 & \multirow{3}{*}{0,00} \\
\hline Yes & 2 & 8,7 & 21 & 91,3 & 23 & 100,0 & \\
\hline Total & 147 & 81,7 & 33 & 18,3 & 180 & 100,0 & \\
\hline
\end{tabular}

Table 2 above shows that of the 157 respondents who did not experience a multigravida pregnancy, $7.6 \%$ experienced macrosomia, and $92.4 \%$ did not experience macrosomia. Meanwhile, of the 23 respondents who experienced multigravida pregnancies, $91.3 \%$ experienced macrosomia and $8.7 \%$ did not. The percentage of macrosomia in women who had multigravida pregnancies was higher than that of macrosomia in women who did not have multigravida pregnancies. Based on the results of the chi-square test, the $\mathrm{p}$ value $=0.000$ ( $\mathrm{p}$ $<0.05$ ), which means that statistically there is a significant relationship between the multigravida pregnancy factor and the occurrence of macrosomia in infants at the Atikah Midwife Clinic for the 2018-2020 period.

Table 3. Cross Tabulation of Maternal Age Factors Associated with Macrosomia Incidence in Infants

\begin{tabular}{|c|c|c|c|c|c|c|c|}
\hline \multicolumn{8}{|c|}{ The Occurrence of Macrosomia in Babies } \\
\hline \multirow{2}{*}{$\begin{array}{c}\text { Maternal } \\
\text { Age Factor }\end{array}$} & \multicolumn{2}{|c|}{ No Macrosomia $(\leq 4000 \mathrm{~g})$} & \multicolumn{2}{|c|}{ Macrosomia $(>4000 \mathrm{~g})$} & \multicolumn{2}{|c|}{ Total } & \multirow{2}{*}{ P-Value } \\
\hline & $\mathrm{F}$ & $\%$ & $\mathrm{~F}$ & $\%$ & $\mathrm{~F}$ & $\%$ & \\
\hline $\begin{array}{l}35 \text { years } \\
\text { old }\end{array}$ & 115 & 91,3 & 11 & 8,7 & 126 & 100,0 & \multirow{3}{*}{0,00} \\
\hline $\begin{array}{l}>35 \text { years } \\
\text { old }\end{array}$ & 32 & 59,3 & 22 & 40,7 & 54 & 100,0 & \\
\hline Total & 147 & 81,7 & 33 & 18,3 & 180 & 100,0 & \\
\hline
\end{tabular}

Table 3 above shows that of the 126 respondents aged 35 years, 6.1\% experienced macrosomia and $63.9 \%$ did not. Meanwhile, from 54 respondents aged $>35$ years, $40.7 \%$ experienced macrosomia and $59.3 \%$ did not. The percentage of macrosomia in mothers $>35$ years of age is higher than the incidence of macrosomia in mothers 35 years of age. Based on the results of the chi-square test, $p$ value $=0.000(p<0.05)$, which means that statistically it shows a significant relationship between maternal age and the occurrence of macrosomia in infants at the Atikah Midwife Clinic for the 2018-2020 period.

Table 4. Cross Tabulation of Gestational Age Factors Associated with

Macrosomia Incidence in Infants

\begin{tabular}{|c|c|c|c|c|c|c|c|}
\hline \multicolumn{8}{|c|}{ The Occurrence of Macrosomia in Babies } \\
\hline \multirow{2}{*}{$\begin{array}{l}\text { Pregnancy } \\
\text { Age Factor }\end{array}$} & \multicolumn{2}{|c|}{ No Macrosomia $(\leq 4000 \mathrm{~g})$} & \multicolumn{2}{|c|}{ Macrosomia $(>4000 \mathrm{~g})$} & \multicolumn{2}{|c|}{ Total } & \multirow{2}{*}{ P-Value } \\
\hline & $\mathrm{F}$ & $\%$ & $\mathrm{~F}$ & $\%$ & $\mathrm{~F}$ & $\%$ & \\
\hline 40 weeks & 132 & 91,0 & 13 & 9,0 & 145 & 100,0 & \multirow{3}{*}{0,00} \\
\hline $\begin{array}{l}>40 \\
\text { weeks }\end{array}$ & 15 & 42,9 & 20 & 57,1 & 35 & 100,0 & \\
\hline Total & 147 & 81,7 & 33 & 18,3 & 180 & 100,0 & \\
\hline
\end{tabular}

Table 4 above shows that of 145 respondents with gestational age 40 weeks, $9.0 \%$ experienced macrosomia and $91.0 \%$ did not. Meanwhile, from 35 respondents with gestational age $>40$ weeks, $57.1 \%$ experienced macrosomia and $42.9 \%$ did not experience macrosomia. The percentage of macrosomia in women with gestational age $>40$ weeks was higher than the incidence of macrosomia in women with gestational age 40 weeks. Based on the results of the chi-square test, the $\mathrm{p}$ value $=0.000(\mathrm{p}<0.05)$, which means that statistically it shows a significant relationship between the gestational age factor and the occurrence of macrosomia in infants at the Atikah Midwife Clinic for the 2018-2020 period.

\subsection{Discussion}

\subsubsection{Factors of History of Giving Birth to Large Babies Associated with the Incidence of Macrosomia in Babies}

Pregnant women who have a history of giving birth to macrosomic babies will have a 5-10 times greater risk of giving birth to macrosomic babies again than women who have never given birth to macrosomic babies 
because generally the weight of a baby who will be born next will increase by about 80 to 120 grams [2]. The results of this study are in line with Susianti's 2017 research on factors related to the incidence of macrosomia at Sawerigading Palopo Hospital that of the 16 respondents there were mothers who had a history of giving birth to macrosomia before in high-risk pregnancies totaling 6 respondents $(37.5 \%)$. If a pregnant woman has a history of giving birth to a macrosomic baby before, then in the next delivery or pregnancy the risk is 5-10 times to give birth to macrosomia again [7]. The researcher's assumption is that mothers with a history of giving birth to macrosomia in the past can influence the birth of macrosomic babies in subsequent pregnancies. This opinion is strengthened in this study where the results show that a history of macrosomia birth is associated with the incidence of macrosomia.

\subsubsection{Multigravida Pregnancy Factors Associated with Macrosomia Incidence in Infants}

There is a tendency for the birth weight of the second child and so on to be greater than the first child because of the weight gain of about 80 to 120 grams in subsequent pregnancies and excessive maternal weight gain during pregnancy, the portion of food consumed by pregnant women will affect the mother's weight (Maryunani and Puspita , 2014). The results of this study are in line with Osok's 2014 research on the description of pregnancy with macrosomia outcomes for the January-December period at RUSP Prof. Dr. R. D. Kandou Manado proved that as many as 128 respondents $(87.1 \%)$ in multigravida pregnancies with the incidence of macrosomia [10].

\subsubsection{Male Gender Factors Associated with Macrosomia Incidence in Infants}

A mother carrying a baby boy, in general, a male fetus will have a heavier body weight than a female baby [4]. The results of this study are in line with Merita's 2015 research on risk factors for babies born with obesity (macrosomia). \%). (Merita, 2015). The results of Osok's research in 2015 also proved that macrosomia births had the most cases in male babies as many as 85 respondents $(57.8 \%)$. Based on the baby's weight at RSUP Prof. Dr. R. D. Kandou Manado for the period of January-December 2014 found the most cases in infants weighing 4,000-4,250, namely 88 respondents $(59.86 \%)$. The lowest cases were found in body weight above 5,000 grams, namely 2 respondents in male infants with macrosomia events [19]. The researcher's assumption is that gender is one of the factors associated with macrosomia because of the presence of androgen hormones which are more abundant in men where this hormone as described previously can affect the growth of skeletal muscle tissue so that male babies are more at risk of having excess weight during pregnancy.

\subsubsection{Maternal Age Factors Associated with Macrosomia Incidence in Infants}

Age conditions in pregnant women that need to be watched out for are conditions that may affect the emergence of difficulties in childbirth, for example under 20 years of age at this age the uterus and pelvis have not developed properly so the possibility of experiencing difficult delivery and pregnancy poisoning or free eclampsia. Meanwhile, over the age of 35 years in general, bleeding often occurs, the risk of congenital defects and the risk of giving birth to a macrosomic baby. The age of the mother is closely related to the weight of the baby at birth, the older the age of the pregnant woman, the more energy needed. Pregnant women aged 20 years and $>35$ years have a high risk of getting pregnant because it will endanger the health and safety of the fetus [8].

Previous research in the 2012 period also had the same result, namely the most cases of macrosomia infants at the age of 30-34 years. This is because the older the pregnant mother, the more weight the baby will be born. The results of Osok's 2014 study on the description of pregnancies with macrosomia in the JanuaryDecember period at Kandou Hospital Manado proved the number of pregnancies with macrosomia as many as 202 of the 3,347 cases recorded and the most of them were aged 35-40 years (42 cases) [23]

Based on age, researchers assume that the age of pregnant women affects the occurrence of macrosomia in infants. Maternal age less than 20 years and more than 35 years have the potential to experience macrosomia in infants compared to maternal age between 20-35 years. This is caused by several factors, including the condition of the uterus and pelvis that have not developed properly, frequent bleeding and so on so that the possibility of having a difficult delivery and pregnancy poisoning and causing macrosomia in the baby.

\subsubsection{Pregnancy Age Factors Associated with Macrosomia Incidence in Infants}

The results of this study are in accordance with the theory that postterm pregnancy has a close relationship with mortality, morbidity, perinatal, or macrosomia. Because the fundamental changes that occur in postterm pregnancy stem from the ability of the placenta to provide nutrients and oxygen as well as the ability of other functions. If the function of the placenta is still good enough, it can cause fetal growth and development to continue, so that body weight continues to increase even though it is slow, it can reach more than 4000 grams, which is called a macrosomic baby. [14]. Of the 35 respondents with gestational age $>40$ weeks, $57.1 \%$ experienced macrosomia and $42.9 \%$ did not. The percentage of macrosomia in women with gestational age $>40$ weeks was higher than the incidence of macrosomia in women with gestational age 40 weeks. 
Giving birth past the due date, for example, a baby has not yet been born at 40 weeks of gestation, will increase the risk of macrosomia, the longer the pregnancy, the greater the risk of the fetus becoming obese due to unstoppable fetal growth [21]. The length of pregnancy can affect the weight of the fetus, the older the gestational age, the weight of the fetus in the womb will continue to increase. The placenta in male fetuses can grow more adequately and work more efficiently. This causes the supply of food from the mother to the fetus to work optimally, so that it can stimulate the growth of the fetus in the womb (Eriksson et al, 2010). The duration of pregnancy from ovulation to parturition is approximately 280 days (40 weeks), and no more than 300 days (43 weeks). Pregnancy 40 weeks is called a pregnancy term (term). Pregnancy more than 41 weeks is called a postmature pregnancy. Gestational age can determine fetal weight, the older the gestational age, the fetal weight will also increase [13].

The fetus in the uterus will continue to grow and develop if the condition of the placenta is still good at an increasing gestational age. This can lead to pregnancy complications such as reduced amniotic fluid and the occurrence of macrosomia [18]. Based on the results of the chi-square test, the $\mathrm{p}$ value $=0.000(\mathrm{p}<0.05)$, which means that statistically it shows a significant relationship between the gestational age factor and the occurrence of macrosomia in infants at the Atikah Midwife Clinic for the 2018-2020 period. The results of this study are in accordance with the theory that postterm pregnancy has a close relationship with mortality, morbidity, perinatal, or macrosomia. Because the fundamental changes that occur in postterm pregnancy stem from the ability of the placenta to provide nutrients and oxygen as well as the ability of other functions. If the function of the placenta is still good enough, it can cause fetal growth and development to continue, so that body weight continues to increase even though it is slow, it can reach more than 4000 grams, which is called a macrosomic baby. [19].

The results of this study are also supported by Osok's 2014 research on the description of pregnancy with macrosomia outcome in the January-December period at Prof. RSUP. Dr. R. D. Kandou Manado proved that as many as 80 respondents $(54.42 \%)$ at $37-40$ weeks of gestation had macrosomia [10]. Researchers assume that the factor of gestational age is strongly associated with the occurrence of macrosomia in infants. Giving birth past the due date, for example, the baby has not yet been born at 40 weeks of gestation, will increase the risk of macrosomia. This event is possible due to multifactorial factors such as a previous history of macrosomia and maternal obesity. The mother may have given birth to macrosomia and repeated in this pregnancy.

\section{CONCLUSION}

Based on the description of the results and discussion, it can be concluded that the history of giving birth to large babies is related to the incidence of macrosomia in infants at the Atikah Midwife Clinic for the 2018-2020 period, where the percentage of macrosomia events in mothers who have a history of giving birth to large babies is higher than the incidence of macrosomia in mothers. who never gave birth to a big baby. The results showed that of the 12 respondents who had a history of giving birth to large babies, $91.7 \%$ experienced macrosomia in infants and $8.3 \%$ did not experience macrosomia in infants. Factors of multigravida pregnancy related to the incidence of macrosomia in infants at the Atikah Midwife Clinic for the 2018-2020 period, where the percentage of macrosomia events in mothers who experienced multigravida pregnancies was higher than the incidence of macrosomia in mothers who did not experience multigravida pregnancies. The results showed that of the 23 respondents who had multigravida pregnancies, $91.3 \%$ experienced macrosomia and $8.7 \%$ did not. Male sex factors related to the incidence of macrosomia in infants at the Atikah Midwife Clinic for the 2018-2020 period, where the percentage of macrosomia in mothers with male pregnancies was higher than the incidence of macrosomia in women with female calamine pregnancies. The results showed that from 88 respondents with male pregnancies, $25.0 \%$ experienced macrosomia in infants and $75.0 \%$ did not experience macrosomia. Maternal age factors related to the incidence of macrosomia in infants at the Atikah Midwife Clinic for the 2018-2020 period, where the percentage of macrosomia events in mothers aged $>35$ years was higher than the incidence of macrosomia in mothers aged $\leq 35$ years. The results showed that from 54 respondents aged $>35$ years, $40.7 \%$ experienced macrosomia and $59.3 \%$ did not. The factor of gestational age related to the incidence of macrosomia in infants at the Atikah Midwife Clinic for the 20182020 period, where the percentage of macrosomia events in mothers with gestational age $>40$ weeks was higher than the incidence of macrosomia in mothers with gestational age 40 weeks. The results showed that of the 35 respondents with gestational age $>40$ weeks, $57.1 \%$ experienced macrosomia and $42.9 \%$ did not.

\section{ACKNOWLEDGEMENTS}

Author thanks my research team. In most cases, sponsor and financial support. 


\section{REFERENCES}

[1] Hidayat, Aziz Alimul, Midwifery Research Methods \& Data Analysis Techniques. Vol. 1, $1^{\text {st }}$ ed, Salemba Medika, Jakarta, Indonesia, 2011.

[2] Maryunani, Anik. Eka Puspita, Maternal and Neonatal Emergency Care, Vol. 2, 2 $2^{\text {nd }}$ ed, Trans Info Media, Jakarta, Indonesia, 2014.

[3] Notoadmojo, S, Health Research Methodology, Vol. 1, $3^{\text {rd }}$ ed, Rineka Cipta, Jakarta, Indonesia, 2012.

[4] Rukiyah, Ai Yeyeh Lia Yulianti, Midwifery Care 4 Pathology, Vol. 2, $2^{\text {nd }}$ ed, Trans Info Media, Jakarta, Indonesia, 2017.

[5] Sugiyono, Quantitative, Qualitative and R\&D Research Methods. Vol. 1, $1^{\text {st }}$ ed, Alfabeta, Bandung, Indonesia, 2011.

[6] Sukirno, Midwifery Care 4 Pathology, Vol. 1, $2^{\text {nd }}$ ed, Trans Info Media, Jakarta, Indonesia, 2017.

[7] Susianti. Factors Associated with Macrosomia Occurrence, Vol. 1, $1^{\text {st }}$ ed, RSUD Saweriganding, Palopo, Indonesia, 2017.

[8] Merita. "Risk Factors for Babies Born Fat (Macrosomia) in Indonesia". vol. 6, no. 1, pp. 77-80, Abbrev. June, 2018.

[9] Ningsih, WP, Farida K. The Relationship of Pregnant Women's Knowledge About Macrosomia With Nutritional Patterns During, Vol. $1,3^{\text {rd }}$ ed, Umbulharjo, Yogyakarta, 2019

[10] Osok S, John W, Maya M, Overview of Pregnancy with Macrosomia Outcome, Vol. 1, $1^{\text {st }}$ ed, RSUP Prof. Dr. R. D. Kandou Manado. Indonesia, 2014

[11] Susianti. Factors Associated with Macrosomia Occurrence, Vol. 1, $1^{\text {st }}$ ed, RSUD Saweriganding, Palopo. Indonesia, 2017.

[12] Clausen, T., Burski, T.K., Oyen, N., Godang, K., Bollerslev, J., Henriksen, T., Maternal anthropometric and metabolic factors in the first half of pregnancy and risk of neonatal macrosomia in term pregnancies. A prospective study. Eur. J. Endocrinology. pp. 153, 887-894. 2005. https://doi.org/10.1530/eje.1.02034

[13] Elie, N., Maternal and neonatal complications of macrosomia. Trop. Doct. Sage Journals. 44, pp 201-204. 2014. https://doi.org/10.1177/0049475514539479.

[14] Gaudet, L., Ferraro, Z.M., Wen, S.W., Walker, M. Maternal Obesity and Occurrence of Fetal Macrosomia: A Systematic Review and Meta-Analysis. BioMed Res. Int. 2014. https://doi.org/10.1155/2014/640291.

[15] Ikeako, L., Ezegwui, H., Egbuji, C.,. Fetal macrosomia: Obstetric outcome of 311 cases in UNTH, Enugu, Nigeria. Niger. J. Clin. Pract. 14, pp 322-330. 2011. https://doi.org/10.4103/1119-3077.86777.

[16] Lu, J., Wu, J., Zhao, Z., Wang, J., Chen, Z. Circulating LncRNA Serve as Fingerprint for Gestational Diabetes Mellitus Associated with Risk of Macrosomia. Cell. Physiol. Biochem. 48, pp 1012-1018. 2018. https://doi.org/10.1159/000491969.

[17] Najafian, M., Cheraghi, M, Occurrence of Fetal Macrosomia Rate and Its Maternal and Neonatal Complications: A 5-Year Cohort Study. ISRN Obstet. Gynecol, 2012. https://doi.org/10.5402/2012/353791.

[18] Nkwabong, E., Nzalli Tangho, G.R., Risk Factors for Macrosomia. J. Obstet. Gynaecol. India 65, pp 226-229. 2015. https://doi.org/10.1007/s13224-014-0586-4.

[19] Olokor, O.E., Onakewhor, J.U., Aderoba, A.K., Determinants and outcome of fetal macrosomia in a Nigerian tertiary hospital. Niger. Med. J. Assoc. 56, pp 411-415. 2015. https://doi.org/10.4103/0300-1652.171622

[20] Wang, N., Ding, Y., Wu, J., Effects of pre-pregnancy body mass index and gestational weight gain on neonatal birth weight in women with gestational diabetes mellitus. Early Hum. Dev. 124, pp 17-21. 2018. https://doi.org/10.1016/j.earlhumdev.2018.07.008

[21] Pates, J.A., McIntire, D.D., Casey, B.M., Leveno, K.J., Predicting Macrosomia. J. Ultrasound Med. 27, pp 39-43. 2008. https://doi.org/10.7863/jum.2008.27.1.39

[22] Srichumchit, S., Luewan, S., Tongsong, T., Outcomes of pregnancy with gestational diabetes mellitus. Int. J. Gynecol. Obstet. 131, pp 251-254. 2015. https://doi.org/10.1016/j.ijgo.2015.05.033

[23] Usta, A., usta, C.S., Yildiz, A., Ozcaglayan, R., Dalkiran, E.S., Savkli, A., Taskiran, Frequency of fetal macrosomia and the associated risk factors in pregnancies without gestational diabetes mellitus. Pan Afr. Med. J. pp 26-35. 2017. https://doi.org/10.11604/pamj.2017.26.62.11440

[24] Akindele R N, Audu L I, Mokuolu O A . Macrosomic births in abuja: A case-control study of predisposing factors and early neonatal outcome. Niger J Clin Pract, pp 124-132. 2017. https://doi.org/ 10.4103/1119-3077.196060

[25] Charles and Anna, Bersahabat dengan Diabetes Mellitus Tipe 2. Vol. 2, $2^{\text {nd }}$ ed, Penebar Plus Depok, Indonesia, 2010. 